\title{
Research on Green Design Strategy of Office Building
}

\author{
Hong Chen ${ }^{1 *}$, Wei Luo ${ }^{1}$, Fengbing Zhao ${ }^{2}$, Limei Geng ${ }^{1}$, Shiyun Cheng ${ }^{3}$ \\ ${ }^{1}$ China Power Construction Group EAST CHINA SURVEY DESIGN \& Research Institute Co. Ltd. Hangzhou China 310014 \\ ${ }^{2}$ Civil Engineering College of Chongqing Jiaotong University Chongqing China 400074 \\ ${ }^{3}$ Communition Bureau of Nanchuan District Chongqing City Chongqing China 408400
}

\begin{abstract}
Green building design refers to reducing the energy consumption of buildings through the use of energy-saving and environmentally-friendly technologies during the design and construction of buildings. The consumption of water resources and electric energy in office buildings is significantly higher than that of ordinary residential buildings, which has a greater impact on the environment during the construction process. Therefore, the use of green building design in the design of office buildings plays an important role in reducing building energy consumption. This article takes an office building in Chongqing as an example to explain the green optimization design and provide support for subsequent related constructions.
\end{abstract}

\section{Introduction}

In the process of rapid economic development, the initial development of mankind started from the development and utilization of natural resources [1-5]. In the process of development, mankind constantly seeks from nature. However, the changes of modern ecological environment and climate abnormalities are all excessive. The consequences that nature demands are also punishments for people. Under the current development situation, we are facing new challenges given to us by nature, and it is also a critical period for us to adjust the development direction of the industry. In the development process of the construction industry, green economy, energy saving, emission reduction, and environmental protection have become the themes of development and direction of further expansion [6-9]. In the design work, it is also necessary to fully consider the work requirements in this area and do a good job in design work. Then, the harmonious development of human and nature can be promoted. Since office buildings have different characteristics from other buildings, the required strategies are comprehensively selected according to factors such as use functions and property holdings. When the office building is completed and ready for actual use, the subsequent maintenance and operation must be implemented in the design of the green building. When choosing green energy-saving equipment, the actual situation in the later period, such as simple and easy operation, durability, should be taken into consideration. At the same time, it should also be considered from the perspective of users, such as initial capital investment, subsequent maintenance costs, investment return period, effective drainage of office and rent. So, it is necessary to meet the social demand for green energy saving, and reduce as much as possible at the same time [10-13].
Take a public building in Chongqing as an example. The project is located in the south of plot F40-1-1 in Konggang New Town, Chongqing, which belongs to administrative building land. The land is surrounded by municipal roads, with Tongmao Avenue on the south side, Chunhua Avenue on the east side, Chuntong Road on the west side, and Gongyuan Beiyi Road on the north side. The site location is very advantageous. The land area of the project is 24129.00 square meters, and the building area is 44760.26 square meters. The total building area of the application review part reaches 44760.26 square meters. The above ground area is 32853.86 square meters, and the underground area is 11906.40 square meters with the project building density of $26.40 \%$, the plot ratio of 1.36 , and the green area ratio of $35.17 \%$. The project has 6 floors above ground with a height of 30.50 meters. The 6 floors above the ground are the comprehensive archives building. The main function of the first floor is the exhibition hall. The second floor is mainly used as the exhibition hall and archives service room. The main function of the third floor is the urban construction archive room. The main function of the first floor is the archives warehouse, and the sixth floor is mainly used for the technical and business rooms of the archives, which belongs to a class of high-rise public buildings. There is one underground floor with 4.5 meters high, where 271 small cars (including 33 electric car charging parking spaces) can be parked in the underground garage. In order to effectively ensure that the project can be implemented in accordance with the relevant requirements of green public buildings, it is necessary to conduct research and analysis on the relevant concepts and strategies of green building design.

\footnotetext{
${ }^{*}$ Corresponding author: Hong Chen chen_h7@hdec.com
} 


\section{Main features of office buildings}

\subsection{Energy conservation and environmental protection}

Office buildings consume a lot of energy, in which the energy consumption of air conditioning, heating, ventilation, and photoelectric lighting account for a large proportion of the total energy consumption of office buildings. At the same time, from the perspective of energy consumption, there are obvious differences between office buildings and residential buildings. This is specifically reflected in the distribution time of energy consumption. The energy load of office buildings is relatively concentrated. In the case of the same envelope structure, compared with general residential buildings, the office building has a larger cooling load and a smaller heat load.

\subsection{Outdoor environment}

As the urbanization process continues to accelerate, the number of office buildings is increasing. Due to the particularity of office buildings, most of them are located in urban centers, and there are usually large financial plazas or life plazas nearby to meet people's needs for leisure, entertainment, food, and shopping. At the same time, as an office place, the office building is relatively densely populated, with many traffic routes and usually intricate in the area where it is located. There are close connections with other areas of the city, and the surrounding municipal facilities are relatively complete. Considering the above-mentioned factors comprehensively, it will inevitably have a certain impact on its surrounding environment and the urban environment, transportation lines, and municipal facilities.

\section{Main principles of green building design}

\subsection{Energy conservation and environmental protection}

Energy conservation and environmental protection are the most basic requirements in green building design. When using green building design concepts to design office buildings, the principles of energy conservation and environmental protection should also be adhered to. In the design process, we must first analyze the use of energy and the possible impact on the surrounding environment in order to avoid common energy waste in the design and construction of office buildings. It is also necessary to strengthen the use of new energy-saving technologies and new energy in design and construction.

\subsection{Comfortability}

When designing an office building, it is also necessary to fully consider the use performance of the building.
While effectively reducing the energy consumption of the building, it avoids the deterioration of the use performance due to energy saving. Hence, the building maintains good lighting and ventilation effects, so as to fully meet the needs of users' demands.

\subsection{Feasibility}

In the design of office buildings, it is necessary to fully implement the concept of energy conservation and environmental protection, but also to consider whether the construction plan is feasible. On the one hand, it is necessary to ensure that energy-saving and environmental protection technologies can achieve good results in the use of office buildings. On the other hand, it is necessary to consider the required costs and economic benefits to prevent the problem of wasting funds.

\section{Key Points of Green Building Design for Office Buildings}

During the design of the green buildings, especially the office buildings, several key points should be concerned to improve the comprehensive benefits. Figure 1 shows the three main aspects should be paid attention. The detail descriptions are given in the followings.

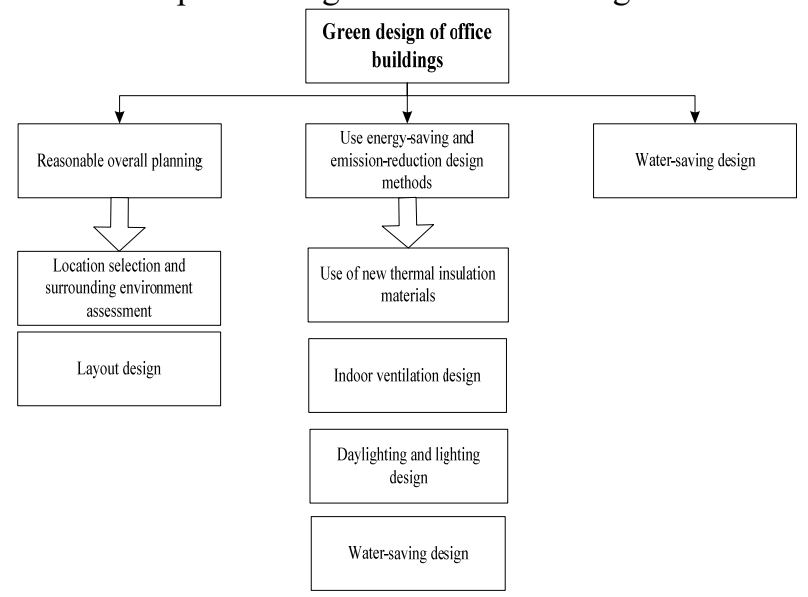

Figure 1 Key points during the green design for office buildings

\subsection{Reasonable overall planning}

In the design and planning stage of office buildings, we must first use green design concepts to make reasonable planning and preparations. The specific planning content mainly includes location selection, layout design and surrounding environment survey. Through the above work, a reasonable energy utilization plan can be derived, which is more conducive to achieving the goal of reducing energy consumption.

\subsubsection{Location selection and surrounding environment assessment}

When selecting the location of an office building, it is necessary to make a detailed assessment of the climate 
characteristics and surrounding environment of the office building. The assessment content includes natural conditions such as climatic characteristics, wind direction and speed, light conditions, relative humidity, and the surrounding area of the office building (e.g., traffic conditions and environmental quality). In terms of specific evaluation methods, on-site inspections and computers can be used to simulate various factors around the office building, and then the office building can be reasonably laid out.

\subsubsection{Layout design}

In the overall planning stage, the correct layout design of the office building must be made. In the design process, the location of the office building and the infrastructure conditions must be considered. It is also necessary to make a reasonable choice of the length-to-width ratio of the office building. Generally, the long sides of the building should be arranged in the north-south direction, and the main functional rooms can also be designed as corridors, which is conducive to improving the lighting and ventilation effects of the office building.

\subsection{Use energy-saving and emission-reduction design methods}

In the design of energy saving and environmental protection of buildings, it is specifically divided into active energy saving and passive energy saving. Active energy saving refers to the use of various energy saving equipment to rationally use energy. Passive energy saving means that through the design of the enclosure structure. A good thermal insulation effect is achieved and the energy consumption of the building itself is effectively reduced. Under the green building design concept, the following design methods can be used to achieve the purpose of energy saving and environmental protection.

\subsubsection{Use of new thermal insulation materials}

Wall structure and doors and windows are the key parts of building energy saving. Through the reasonable design of building envelope structure and the use of new thermal insulation materials, the building's thermal insulation performance can be improved. Also, the demand for heating equipment and air-conditioning can be reduced, thereby achieving energy saving and emission reduction. In the design and construction of office buildings, the following types of new thermal insulation materials can be used. In the energy-saving design of the wall structure, materials such as polystyrene board, concrete hollow block, sandwich composite wall can be used. The above-mentioned materials have good thermal insulation effect, can play an effective energy-saving effect, and are conducive to saving building materials. In the energy-saving design of doors and windows, energy-saving glass can be used. For office buildings with glass curtain wall design, the use of double silver glass can effectively isolate solar radiation and provide good heat preservation on the basis of ensuring light transmission performance. effect. In addition, the use of thermal insulation curtains can effectively block light from entering the room and have a certain thermal insulation effect.

\subsubsection{Indoor ventilation design}

In the design of office buildings, reasonable ventilation design has a certain effect on reducing the use of air conditioning and ventilation systems. Specifically, the following methods can be used to maintain good indoor ventilation conditions. First, you can make full use of natural ventilation to effectively control the length, width, and height ratio of the window when designing, and you can also design the window sash as a casement window to improve the natural ventilation capacity of the room. It is also possible to effectively improve the operating efficiency of air-conditioning through the rational application of air-conditioning equipment. For example, frequency conversion technology can be used to reduce energy consumption by adjusting the operating speed of fans and motors.

\subsubsection{Daylighting and lighting design}

The use of lighting equipment accounts for a relatively high proportion of the energy consumption of office buildings, and a reasonable indoor lighting design can effectively reduce the use of lighting equipment. When designing indoor lighting, computer technology can be used to simulate the lighting situation, and the window opening method and light guide method can be selected according to the specific local conditions to achieve the maximum use of natural light and achieve the purpose of high efficiency and energy saving [2]. In lighting design, office buildings should strengthen the application of high-efficiency lighting systems. Among them, LED lighting systems have good energy-saving effects and have a relatively long service life, which is conducive to achieving green and environmental protection.

\subsubsection{Water-saving design}

Among the energy consumption of office buildings, water consumption accounts for about $20 \%$, and it is of great significance to adopt water-saving design in the design of office buildings. In terms of specific design methods, water-saving appliances can be selected and rainwater recycling should be strengthened. For example, an office building installed two 1000L water storage buckets on the roof terrace, which can collect rainwater on the roof, and then use it for toilet water after treatment, which has a significant water saving effect.

\subsection{Strengthen the use of new energy}

Traditional energy is mainly used in the design of traditional office buildings. Under the concept of green building design, the development and utilization of new energy should be strengthened, and the purpose of 
sustainable development should be achieved through the use of renewable energy. At present, solar energy and wind energy are used in the design of office buildings and have strong applicability. For example, solar water heating systems are widely used. Install solar water heaters on the top of office buildings, and realize the effective use of solar energy through the use of heat collectors and heat exchangers. In the specific design, it is also necessary to consider the coordination and unity of the new energy utilization device and the building in order to achieve the most ideal application effect. For example, in the installation of solar water heating systems, it is necessary to consider the sunshine time and the amount of solar radiation at the location of the office building, as well as the water consumption of the building, the carrying capacity of the building, and the situation of the installation site. Through reasonable design and planning of the above factors, the effective use of new energy can be realized to the greatest extent.

\section{Conclusion}

This paper takes a public building in Chongqing as the starting point, then discusses the main idea of green design strategies of office buildings. In the context of widespread attention to environmental issues, the application of green building design is of great significance for achieving sustainable development. When using the green building design concept for office building design, it is necessary to make an overall plan for the location and layout of the office building on the basis of adhering to the main design principles. At the same time, various energy-saving and emissionreduction design methods must be actively used to minimize Building energy consumption. In addition, the use of new energy should be strengthened, which is more conducive to achieving the goal of green and environmental protection.

\section{Acknowledgement}

This work is supported by Research Project of China Power Construction Group East China Survey Design \& Research Institute Company Limited (KY2020-JG-3201-2021).

\section{References}

1. Pan, Y., R. Yin, and Z. Huang . "Energy modeling of two office buildings with data center for green building design." Steel Construction 40.7(2008):1145-1152.

2. Ding, Z., Fan, Z., Tam, V. W. Y., Bian, Y., Li, S. , \& Illankoon, I. M. C. S. , et al. (2018). Green building evaluation system implementation. Building and Environment, 133(APR.), 32-40.

3. Pan, B. Y. , \& Liu, J. P. . (2011). Building the assessment and evaluation system of green residential area. Applied Mechanics \& Materials, 71-78, 134-137.
4. Yan, \& Bing. (2012). Research on evaluation principle and method for green building. Applied Mechanics \& Materials, 193-194, 125-128.

5. Bao, X. Y. , \& Wang, Q. C. . (2013). A comprehensive evaluation study of green building degree based on the fuzzy comprehensive evaluation. Applied Mechanics \& Materials, 256-259, 30333037.

6. Liu, L., Lin, Y., Wang, L., Cao, J., Wang, D. , \& Xue, P. , et al. (2017). An integrated local climatic evaluation system for green sustainable eco-city construction: a case study in shenzhen, china. Building \& Environment, 114, 82-95.

7. Yan, \& Bing. (2012). Research on evaluation principle and method for green building. Applied Mechanics \& Materials, 193-194, 125-128.

8. Liu, S. L. , Hao, P. L. , \& Song, Y. X. . (2011). An exploration of establishment of green building evaluation standards weight system based on analytic hierarchy process. Applied Mechanics \& Materials, 71-78, 4166-4169.

9. Fan, B. , \& Zhao, X. Y. . (2014). Comparing the core evaluation system for green building at home and broad. Applied Mechanics and Materials, 507, 163-167.

10. Mao, D. , Zhou, K. , Zheng, S. J. , Liu, Y. D. , \& Liu, Y. P. . (2011). Research on evaluation system of green building in china. Advanced Materials Research, 224, 159-163.

11. Wang, Q. , Feng, X. P. , Tian, B. , \& Li, C. T. . (2014). Study on the evaluation index system and evaluation method for the building energy-saving and green building demonstration zone. Advanced Materials Research, 962-965(12), 1612-1615.

12. Zhang, X., Zhan, C. , Wang, X. , \& Li, G. . (2019). Asian green building rating tools: a comparative study on scoring methods of quantitative evaluation systems. Journal of Cleaner Production, 218(MAY 1), 880-895.

13. Qi-Gan, S. , James, L. , Sung-Shun, W. , \& YenChing, C. . (2018). Improving the green building evaluation system in china based on the danp method. Sustainability, 10(4), 1173. 